\title{
A Saúde da Nossa Gente: a popularização da ciência nos veios da educação não formal
}

Antonio José Silva Oliveira e Ana Lourdes Alves de Araújo

\section{Resumo}

0 presente artigo centra sua investigação na divulgação científica, popularização da ciência ou compreensão pública da ciência, termos usados neste trabalho com o mesmo sentido, a fim de buscar aproximações entre as ações de divulgar e educar. Para tanto, utilizou-se a História Oral como metodologia, uma vez que, por esse aspecto da pesquisa qualitativa, é possível explorar as relações entre história e memória, essência desta pesquisa. A história e memória dos programas Alimentação é Vida e A Saúde da Nossa Gente, veiculados na Rádio Educadora Rural do Maranhão, nas décadas de 1980 e 1990, foram realizadas por meio do diálogo com as fontes: narrativas, gravações dos programas sob 0 veio teórico da Educação Popular de Paulo Freire e de estudiosos da educação não formal, que constatam que programas radiofônicos foram importantes instrumentos de educação, permitindo que, temporalmente, a ciência fizesse parte do cotidiano de comunidades rurais do Maranhão.

\section{Palavras-Chave}

Divulgação Científica. Ciência e Tecnologia. Educação Não Formal. Memória da Ciência no Maranhão.

Antonio José Silva Oliveira | antonio.oliveira@ufma.br Doutor em Ciência na área de Física Atômica e Molecular pela Universidade Estadual de Campinas - Unicamp, Brasil. Professor da Pós-Graduação em Educação e Ensino de Física da Universidade Federal do Maranhão - UFMA, Brasil.

Ana Lourdes Alves de Araújo I analourdes@ifma.edu.br Mestre por meio do Programa de Pós-Graduação em Educação da Universidade Federal do Maranhão - UFMA, Brasil.

\section{Introdução}

0 presente artigo é fruto de leituras, reflexões, debates e pesquisas observadas no movimento que envolve 0 diálogo entre pesquisadores nacionais e internacionais em relação ao debate da divulgação científica, sendo que alguns pesquisadores brasileiros, como Ildeu de Castro (UFRJ), Luisa Massarani (Fiocruz), Carlos Vogt (Labjor/Unicamp), Antonio Oliveira (UFMA), entre outros, vêm se destacando como organizadores da produção científica resultante dessa interface.

Essas reflexões possibilitaram-nos perceber que a compreensão pública da ciência é um problema, o qual não se refere apenas à escola, instituição representante da educação formal, mas envolve também ações das mais diversas entidades, em diferentes espaços de atuação da educação não formal.

Tal inferência nos trouxe inquietações que nos instigaram a interrogar sobre a memória da ciência no Maranhão. Nesse sentido, algumas questões apresentavam-se de modo latente, como: 
Quais eram e como ocorriam as atividades de divulgação científica no Maranhão e quando? Qual era a relação existente entre as atividades de divulgação científica e a educação não formal?

Estando em busca das atividades que delinearam vasto repertório discursivo sobre a divulgação científica e a sua relação com a educação não formal, decidimos analisar dois programas veiculados nas décadas de 1980 e 1990: Alimentação é Vida e A Saúde da Nossa Gente, apresentados pela professora Vera Lúcia Rolim Salles, professora do curso de Comunicação da Universidade Federal do Maranhão, cujos conteúdos apresentavam-se com características de difusores da ciência e da educação não formal. Esses programas, portanto, constituíram-se objeto de investigação desta pesquisa.

\section{0 s fundamentos teórico-metodológicos}

Estando delineados os programas radiofônicos Alimentação é Vida e A Saúde da Nossa Gente como objetos da pesquisa, partimos para a definição de uma abordagem metodológica que desse conta de atingir o objetivo que pretendia alcançar o presente estudo. Ou seja, compreender se um programa de divulgação científica pode se constituir em um instrumento de educação não formal e não simplesmente tratar os temas científicos pelo que Bachelard (2007) chama de aspectos mundanos, isto é, quando a divulgação serve apenas para satisfazer curiosidades e causar admiração no público.

Por conta do objeto selecionado, o qual não pode ser quantificado e, dessa forma, sugere um mergulho profundo nas nuances de suas particularidades, decidimos pela pesquisa qualitativa, tendo em vista as possibilidades que essa abordagem metodológica, segundo Deslandes et al. (DESLANDES, 1994), propiciaria, uma vez que precisaríamos percorrer o universo de significados, crenças e valores, os quais compreendem uma análise mais profunda nas relações dos fenômenos e não apenas na operacionalização de variáveis.

Das abordagens da pesquisa qualitativa, optamos pela História Oral, pois, por essa abordagem, é possível explorar as relações entre história e memória, e estudar a história da vida social das pessoas, as questões do cotidiano, ver a História de baixo (THOMPSON, 1992), e isso implica explicar a vida de pessoas comuns por uma lógica da vida coletiva das gerações que vivem no presente.

Portanto, o trabalho com fontes orais, para Silva (SILVA, 2000, p. 1), não é uma tarefa fácil, visto que

0 desafio de um trabalho como este, com fontes orais, está na possibilidade de apreender as tensões entre os grupos sociais e os sujeitos individuais nos contextos em que elas são produzidas. As fontes orais fornecem, potencialmente, elementos que permitem, de uma forma muito mais orgânica, apreender as dinâmicas dos grupos e dos sujeitos em seus afazeres, valores, 
normas, comportamentos, etc. Apreender tudo isso significa trabalhar com a complexidade da realidade social.

Além disso, o trabalho com a complexidade da realidade social permite uma percepção do passado como algo que tem uma continuidade no presente, cujo processo histórico não está acabado.

Meihy (MEIHY, 2005) explica que, no trabalho com fontes orais por meio de entrevistas, vídeos, entre outros, o pesquisador produz uma fonte que possibilita construir a história por ele circunscrita. E isso propicia a utilização de outras fontes historiográficas para a confrontação de dados, o que proporciona não só a ampliação das fontes, mas também da visão que se tem de fonte. É importante ressaltar, ainda, que a História Oral, conforme esse autor, não se reduz a mais uma fonte, pois dispõe de um processo metodológico ético para produzir e realizar fontes.

Ainda sobre o uso da História Oral como fonte, Portelli (1997), em sua experiência na reconstrução da história da gente de Temi ${ }^{1}$, comenta que as fontes orais constituíram-se nas primeiras fontes de conhecimento, apesar de ter utilizado as fontes escritas como sustentação, como suporte e como verificação; porém, eram as entrevistas a base do evento. Esse autor descreve, também, 0 tratamento dado às entrevistas e como realizou a montagem da história. Esses aspectos reforçam a ideia de que as fontes orais são tão importantes quanto os outros documentos utilizados pela historiografia.

Para a coleta de dados na abordagem da História Oral, utilizamos na pesquisa que descrevemos neste artigo, além das entrevistas, cartas dos ouvintes, artigos de jornais, gravações em fitas cassetes e cartilhas publicadas como suportes dos programas.

As entrevistas foram realizadas com a professora e jornalista Vera Salles - idealizadora e locutora dos programas, com o seu aluno Marcelo Amorim e sua aluna Gisélia Castro, que trabalhavam na edição e locução dos programas. Essas narrativas nos ajudaram a reconstruir a trajetória dos dois programas, uma vez que não há registros na memória do rádio maranhense sobre esse tema.

Aliado a essa fonte, buscamos suporte de outras fontes historiográficas, a fim de comparar, verificar e sustentar os dados obtidos nas narrativas referentes aos programas veiculados no período delimitado para nossa investigação, que constitui um espaço entre a década de 1980 e os primeiros anos de 1990.

No entanto, para dialogar com as fontes, foi necessária a utilização de conceitos que se referem à divulgação científica e à educação não formal, com vistas a atingir o objetivo principal desta pesquisa, que é compreender de que 
maneira um programa de divulgação científica pode ser um instrumento de educação não formal.

Julgamos importante esclarecer, logo no início desse percurso, que, para analisar os aspectos da educação não formal no programa radiofônico circunscrito na pesquisa, nos apoiamos em conceitos de educação popular trabalhados por Paulo Freire em sua obra, na medida em que este autor entende "a educação popular como 0 esforço de mobilização, organização e capacitação das classes populares; capacitação científica e técnica [...]" (FREIRE; NOGUEIRA, 1993, p. 19).

Nesse sentido, a educação popular proporciona aos indivíduos uma compreensão crítica que permite uma práxis transformadora da realidade social, política, cultural, em uma perspectiva utópica de uma sociedade igualitária e emancipadora. Cabe ressaltar que, em suas experiências de educação popular, Paulo Freire destacou o diálogo como um de seus princípios pedagógicos, a fim de possibilitar a liberdade e autonomia dos educandos, contrapondose a atitudes passivas.

Autores como Feitosa (FEITOSA, 2007) e Streck (STRECK, 2006) consideram Paulo Freire como um marco histórico da educação popular. Brandão (BRANDÃO, 2006) explica que a década de 1960 foi marcada pelo aparecimento de Paulo Freire e dos círculos populares de cultura, fatos que propiciaram a sistematização de um ideário e de experiências daquilo que hoje conhecemos por Educação Popular.
A utilização da linguagem freireana, como sustentação do discurso que travamos entre divulgação científica e educação não formal, nos possibilitou trabalhar com alguns conceitos que caracterizam o processo educativo popular. Um deles é o conceito de consciência, ou melhor, de conscientização que deve acompanhar 0 processo educativo.

\section{A pessoa conscientizada é capaz de perceber claramente, sem dificuldades, a fome como algo mais do que seu organismo sente por não co- mer, a fome como expressão de uma realidade política, econômica, social, de profunda injusti- ça (FREIRE, 1994, p. 225).}

Além disso, Gohn (GOHN, 2001) delineia as vertentes da concepção de educação não formal, as quais revelam essa forma de educação como uma prática importante no processo de conscientização dos excluídos. Nesse sentido, a educação não formal, para nós, se constitui uma forma de educação que circunscreve um conjunto de práticas que capacitam os indivíduos para diversas ações, como a organização em função de objetivos comunitários e a solução de problemas coletivos; a aprendizagem de habilidades e/ ou desenvolvimento de potencialidades para o trabalho; a aprendizagem dos conteúdos da escolarização formal, escolar, desenvolvidos com ênfase em modalidades alternativas e adaptadas à realidade da população atendida; a aprendizagem política dos direitos dos indivíduos enquanto cidadãos; e 0 uso dos recursos desenvolvidos na e pela mídia, 
pelo convívio social, pelas famílias e pela comunidade como um todo.

É importante enfatizar que a atenção dada a esse tema decorre da observação da inexistência e, portanto, por perceber a necessidade de realização de estudos que resgatem a memória da ciência no Maranhão, tendo em vista que, apesar da quantidade de instituições superiores e produções científicas, a difusão da ciência em nosso estado ainda é muito incipiente.

Sendo assim, a relevância da pesquisa deve-se ao fato de que a divulgação científica, atualmente, vem sendo considerada, por estudiosos da área, como um importante instrumento de inclusão social, devido ao seu estreito vínculo com a educação. Ademais, as necessidades básicas apontadas para 0 exercício da cidadania não compreendem apenas o ensino formal, por excelência, como única instância responsável pela formação do cidadão.

0 desenvolvimento de competências atualmente necessárias para essa formação, como a capacidade de reflexão crítica acerca dos avanços científicos e tecnológicos mais recentes, e de uma base sólida de conhecimentos teóricos fundamentais em ciência e tecnologia, passa a ser tarefa também de outros espaços e suportes sociais que venham a contribuir com a educação, dentre os quais se destacam as iniciativas de divulgação científica.

\section{0 diálogo com as fontes}

A análise e discussão com as fontes coletadas referem-se aos programas Alimentação é Vida e A Saúde da Nossa Gente, exibidos nas décadas de 1980 e 1990, na Rádio Educadora do Maranhão, os quais foram idealizados e apresentados pela Prof ${ }^{a}$ Dra Vera Lúcia Rollim Salles, do Departamento de Comunicação da Universidade Federal do Maranhão.

0 material coletado para essas análises consiste em fitas de gravação do programa; folders e materiais diversos produzidos pela equipe de programação; entrevistas realizadas com a $\operatorname{Prof}^{a}$ Vera Salles e com alguns ex-alunos que participaram do projeto.

\section{0 programa radiofônico Alimentação}

é Vida é fruto da parceria que se criou nos espaços da Universidade Federal do Maranhão entre o Prof. Warwick Estevam Kerr ${ }^{2}$, do Departamento de Biologia, e a Prof ${ }^{a}$ Vera Salles. Em meados da década de 1980, o Prof. Warwick fazia experiências sobre melhoramentos genéticos de plantas encontradas em tribos indígenas e, então, convidou a Prof ${ }^{a}$ Vera Salles para divulgar a sua pesquisa em um programa de rádio. 
É importante destacar que o pesquisador Warwick

Estevam Kerr, cientista de nome internacional, residiu em São Luís durante toda a década de 1980, trabalhando como professor pesquisador do Departamento de Biologia da Universidade Federal do Maranhão.

Incentivada pela proposta do Prof. pesquisador Warwick, a Prof ${ }^{a}$ radialista Vera conversou com 0 advogado Juarez Medeiros - que tinha um programa na Rádio Educadora voltado a esclarecimentos de direitos para a camada popular -, sobre a possibilidade de veicular um programa relativo à alimentação e à saúde naquela emissora.

A partir de então, o ProgramaAlimentação é Vida foi ao ar, na Rádio Educadora, naquela época situada na Rua do Sol. Nos comentários a seguir, a Prof ${ }^{\mathrm{a}}$ Vera Salles descreve aspectos importantes do programa:

Comecei a falar sobre as ervas, e recebia cartas dos ouvintes solicitando sementes. Então recorria ao Prof. Warwick Estevam Kerr, que prontamente atendia. À medida que o programa era exibido, os pedidos de sementes iam aumentando, a ponto de eu ficar horas confeccionando saquinhos de sementes para entregar aos ouvintes. Muitas vezes fui surpreendida, no estúdio, por ouvintes da área Itaqui Bacanga que traziam hortaliças produzidas pelas sementes que receberam no Programa. Essas pessoas queriam explicação sobre como utilizar aqueles produtos que colheram. Então, comecei a divulgar receitas de alimentação com as hortaliças. Essa experiência resultou na construção de uma Cartilha explicativa sobre as denominações científicas, composições vitamínicas e a importância de hortaliças para a saúde das pessoas. $\left({ }^{3}\right)$

Alimentação é Vida foi criado em $1983 \mathrm{e}$ veiculado por dois anos. Muitas foram as demandas apresentadas pelo público ouvinte sobre temas como doenças e tabus referentes à alimentação e à saúde. Além disso, naquela oportunidade, uma nutricionista convidou a Prof ${ }^{a}$ Vera Salles para pesquisar e divulgar o trabalho das agentes de saúde, aspecto que provocou a mudança de denominação do Programa para $A$ Saúde da Nossa Gente.

\section{Programa A Saúde da Nossa Gente atingia} um público considerável da Zona Rural, tendo em vista a quantidade de cartas enviadas pelos ouvintes que interrogavam sobre questões relacionadas à saúde e à alimentação. Portanto, o novo Programa, além de divulgar 0 trabalho das agentes de saúde, conservou um bloco sobre a utilização de plantas alimentícias e medicinais.

A Prof ${ }^{a}$ Vera Salles destacou que, com a veiculação do A Saúde da Nossa Gente, ocorreu um "fato curioso que foi a difusão do soro caseiro para as camadas populares da periferia e zona rural", e, por conta disso, foi convidada pela Pastoral da Criança para proferir palestras sobre essa temática no interior do Estado. 
Relatando sobre essa experiência, a Prof ${ }^{a}$ pesquisadora Vera Salles afirmou o seguinte:

"Descobri uma série de tabus, como o das mães que davam 'engrossado' ${ }^{\text {t4 }}$ para as crianças, pois o leite delas era fraco".

A descoberta desses tabus motivou a abordagem, no Programa, de conteúdos que tratavam da importância do leite materno. Em seguida, foram criados blocos em que 0 médico falava; em outro, a agente de saúde abordava sobre temas demandados tanto pela sua atuação na comunidade quanto pelas cartas recebidas no Programa, como a saúde da mulher, a saúde da criança e a do adolescente.

Na época em que o programa $A$ Saúde $d a$ Nossa Gente era veiculado, a Prof ${ }^{a}$ Vera Salles elaborou um projeto que recebeu apoio do CNPq, para realizar pesquisa de recepção nos interiores do Maranhão. A pesquisa foi dinamizada por seus alunos do curso de Jornalismo. Sobre o resultado da pesquisa, a Prof $f^{a}$ Vera Salles comentou que "[...] em geral, quem ouvia era mulher, elas gostavam muito quando se falava de saúde, orientações para crianças, conselho de pais, alimentação e receitas. Tem um município, Viana, que as mulheres copiavam cadernos e mais cadernos de receitas".
A recepção que teve de $A$ Saúde da Nossa Gente, que se realizou por meio da pesquisa e das cartas dos ouvintes, levou a Prof $f^{a}$ Vera Salles a concluir que o público de seu programa era especificamente a mulher. E, então, passou a veicular, também, o programa Vida de Mulher.

Os dois programas, A Saúde da Nossa Gente e Vida de Mulher, começaram a ser veiculados em dias diferentes: um aos sábados e outro aos domingos. Houve momentos em que foram apresentados ao vivo, direto das comunidades ouvintes. Mas, pela repercussão e pelo apoio que recebeu de diversas entidades e de 0NGs de outros estados, o Vida de Mulher acabou ocupando todo o espaço de que a professora e sua equipe dispunham na radiofonia local.

É importante destacar que, enquanto conseguiu apoio do Fundo das Nações Unidas (Unicef) para custear os programas, foi possível realizá-los. Porém, depois que perdeu esse recurso financeiro, o programa Vida de Mulher teve que sair do ar.

A parceria com o Unicef possibilitou a gravação de fitas cassetes dos programas, as quais foram doadas ao Laboratório de Divulgação Científica Ilha da Ciência, da Universidade Federal do Maranhão (Ilha da Ciência) ${ }^{5}$. Hoje, essas fitas foram todas digitalizadas e estão à disposição dos 
pesquisadores nos arquivos do Ilha da Ciência. Chegamos a ouvi-las por meio do contato que travei com o ex-aluno da Prof ${ }^{a}$ Vera Salles Marcelo Amorim, integrante da equipe de produção, que guardava as fitas, que lhe foram entregues pelo Unicef, anos após os programas terem saído do ar.

0 material sonoro encontrado consiste em fitas cassetes com gravações dos programas Alimentação é Vida, A Saúde da Nossa Gente (programa único), A Saúde da Nossa Gente e Vida de Mulher (programas exibidos na mesma época) e correspondem aos anos de 1987 a 1992.

No acervo de fitas, a maioria das gravações refere-se aos programas $A$ Saúde da Nossa Gente e Vida de Mulher; no entanto, do programa Alimentação é Vida, talvez por ter tido um curto espaço como programa individual, foram encontradas apenas 03 fitas. Entretanto, é importante enfatizar que o Alimentação é Vida aparece como um bloco em várias gravações do programa A Saúde da Nossa Gente.

A estrutura dos programas, de modo geral, seguia o mesmo formato, ou seja, havia sempre um ou dois locutores, a Prof ${ }^{\text {a }}$ Vera Salles e um aluno bolsista do projeto. A pauta do programa consistia em um bloco de comentários sobre temas de saúde relacionados à criança, à adolescência ou à mulher; um bloco intitulado Jornal da Saúde; um bloco de Alimentação é Vida; um bloco para comentários de cartas; e, frequentemente, era reservado um bloco para um entrevistado, que era ligado à área da saúde ou um representante de alguma instituição, normalmente vinculada à temática trabalhada.

Marcelo Amorim, estagiário de A Saúde da Nossa Gente, ao comentar sobre a sua participação como editor e locutor do programa, revela alguns aspectos que destacam a sua dinâmica de veiculação:

Quando comecei a participar do programa, era estagiário da Unicef aqui no Maranhão, então a Profa Vera convidou-me para estagiar no $A$ Saúde da Nossa Gente. Naquela época, já havia outros estagiários e jornalistas. 0 programa era voltado para a população rural e o público-alvo era a mulher, tinha também um viés de apoiar a Pastoral da Criança e os agentes comunitários de saúde, que estavam sendo implantados no Maranhão naquela época. Além disso, o programa tinha a função de levar informação sobre saúde para a população do Maranhão, então eram veiculados conteúdos voltados para esclarecer sobre doenças que eram transmitidas pela água, dicas de alimentação e medicina alternativa. Além disso, as pautas do programa eram motivadas pelas cartas que recebíamos do público, e nós recebíamos muitas cartas de mulheres e famílias, que relatavam ter ouvido 0 programa e ter feito aquela proposta que havia sido apresentada: um lambedor, uma dica de alimentação alternativa; ao mesmo tempo solicitavam que falássemos de alguma doença que estava acontecendo naquele município e que, às vezes, coincidia com as mesmas doenças relatadas por ouvintes de outros municípios. ${ }^{6}$

Os relatos das experiências vivenciadas revelam o importante papel que um programa de rádio 
desempenha sobre a comunicação pública da ciência, tendo em vista que a divulgação científica, conforme afirmam Wynne (WEUNNE, 2005), Lewenstein (LEWENSTEIN, 2003) e Fayard (FAYARD, 1999), enquanto prática social tem a função de estimular a participação cidadã e 0 resgate de vozes e percepções do público acerca de questões que envolvem a ciência e a tecnologia.

Por conta disso, é importante que se considere que o termo divulgação científica ou popularização da ciência pode ser preenchido de sentido, de acordo com o tempo e espaço em que se estejam analisando as relações que se travam entre a ciência e a sociedade e as concepções que se têm de ciência e sociedade em um dado momento.

Nessa perspectiva, esses depoimentos contrariam a visão dominante de popularização da ciência, a qual, segundo Lévy-Leblond (LEVY-LEBLOND, 2006, p. 32), constitui-se um "legado da divisão que se fazia, no século XIX, entre os cientistas, detentores de um conhecimento geral e único, e o público ignorante e indiferenciado ao qual era preciso transmitir o conhecimento".

Considerando a popularização da ciência enquanto campo dinâmico, Fayard (FAYARD, 1999) assevera ser essencial que cada sociedade realize o seu próprio debate acerca desse tema, uma vez que, sendo a divulgação científica um fenômeno social e político, cada cultura elabora questões referentes às suas necessidades, ao mesmo tempo em que desenvolve características próprias de comunicar a ciência ao público. Aspectos esses que se ressaltam na fala de Marcelo Amorim quando ele explica que ...o programa fazia muito sucesso porque ade-
quava a linguagem da comunidade e colocava
as pessoas ao vivo. Além disso, nós tínhamos
muito respeito pelo conhecimento popular por-
que era a história da pessoa; convidávamos
muitos especialistas para esclarecer, mas com
o cuidado de preservar o conhecimento popular. Esse depoimento chama a atenção para a necessidade de se compreender as tendências, ou modelos teóricos que explicam a relação entre ciência e sociedade, uma vez que isso é essencial para que se identifiquem o cientista, o público e a lógica de comunicação que se estabelece entre eles.

\section{Os programas Alimentação é Vida e A Saúde} da Nossa Gente refletiam então, entre outros modelos: o do déficit e o contextual, que, de acordo com Van der Auweraert (2004), mesclamse na dinâmica da sociedade contemporânea e são imprescindíveis na construção de relações sustentáveis entre a sociedade e a ciência.

Porém, observa-se com mais nitidez o modelo da experiência leiga, devido às características que se sobressaem nos relatos das três pessoas que vivenciaram essa experiência, como se constata na afirmação de Gisélia Castro, que também foi aluna da Prof ${ }^{\mathrm{a}}$ Vera Salles e estagiária que trabalhava na produção e locução do programa $A$ Saúde da Nossa Gente. 
0 programa A Saúde da Nossa Gente tinha essa proposta de trabalhar com a sabedoria popular. 0 programa catalogava isso, claro que tínhamos a preocupação de ouvir a ciência, tínhamos a preocupação de fazer a aproximação entre a sabedoria popular e o discurso médico.

Sobre o modelo da experiência leiga, Irwin e Wynne (1996 apud LEWENSTEIN; BROSSARD, 2006) explicam que as atividades de comunicação devem considerar em sua organização o diálogo entre as crenças e o conhecimento científico, de forma que tanto a ciência quanto a sabedoria popular possam contribuir para a resolução de um problema específico, ao mesmo tempo em que contribui para a democratização da comunicação pública da ciência.

Mesmo tendo como predominância o modelo do déficit na realidade brasileira, Massarani e Moreira (MASSARANI, MOREIRA, 2003) juntamente com outros autores, como Leitão e Albagli (LEITÃo, ALBAGLI, 1997), Nietto (NIETTO, 2002) e Martinez (MARTINEZ, 1997), buscam a sua superação, o que se evidencia em iniciativas, mesmo isoladas, como a da veiculação do programa A Saúde da Nossa Gente. Desse modo, como declara Martinez (MARTINEZ, 1997, p. 10), a popularização da ciência e da tecnologia precisa dinamizar ações em que "o conhecimento científico e tecnológico constitua um componente central da cultura, da consciência social e da inteligência coletiva para a efetiva integração cultural, étnica, lingüística, social e econômica".

Para analisar os recortes dos discursos que se inscrevem nos programas escolhidos nesta pesquisa, é importante tentar delinear o contexto e a realidade cotidiana dos seus ouvintes. Para tanto, utilizamos como fonte os textos contidos em Relatório de uma pesquisa de percepção dos programas Vida de Mulher e A Saúde da Nossa Gente, realizada em 19927, por meio do Departamento de Comunicação da UFMA, que teve apoio do CNPq. Esta pesquisa foi feita pelos alunos bolsistas do curso de Comunicação Social, pela jornalista Gisélia Castro e Silva, e coordenada pela Prof ${ }^{a}$ Vera Rolim Salles.

A pesquisa de campo teve como proposta sua aplicação em quatro municípios: São Vicente de Férrer, Matinha, Viana e Bequimão, localizados na Baixada 0cidental Maranhense.

Para termos uma ideia da realidade social em que viviam os ouvintes do programa $A$ Saúde da Nossa Gente, os quais moravam no meio rural do Maranhão, utilizamos o Relatório das pesquisadoras Gisélia Castro e Silva e Ana Cristina Levy Ferreira, que descrevem os municípios pesquisados, ressaltando que Bequimão

É importante destacar que essa pesquisa foi, inicialmente, elaborada apenas para o programa Vida de Mulher, mas como foi percebido, no decurso das entrevistas, que os ouvintes confundiam os dois programas Vida de Mulher e A Saúde da Nossa Gente, "passamos a integrar à pesquisa também a análise de recepção do programa $A$ Saúde da Nossa Gente". Banco de Dados Texto-02. 
é um município pobre e de infra-estrutura precária, com aproximadamente 65 povoados. Desse total apenas três, os maiores, são beneficiados com escolas estaduais: Barroso, Quidiua, Paracatiua. A remuneração dos profissionais da área de educação é baixa. No mês de julho uma professora com magistério recebia 50 mil cruzeiros adicionado a uma gratificação de 20 mil cruzeiros, totalizando 70 mil cruzeiros mensais. 0s professores leigos recebem em média 35 mil cruzeiros. 0 setor de saúde também é insuficiente para atender ao município, Bequimão dispõe somente de um posto médico, onde uma médica examina os pacientes, enviando os casos mais graves aos municípios vizinhos mais equipados ou para São Luís. 0 comércio da cidade é fraco. Desde que o posto do Banco do Brasil foi fechado, as pessoas recebem dinheiro em Pinheiro. Quando retornam a Bequimão já trazem suas compras. Logo 0 dinheiro não circula no comércio local. ${ }^{8}$

0 Relatório sobre a pesquisa realizada no município de Viana destaca as contribuições que os programas exibidos deram aos seus ouvintes.

Sobre isso, as pesquisadoras explicam que os ouvintes geralmente mencionam assuntos abordados no Vida de Mulher e A Saúde da Nossa Gente. No entanto, em particular, o depoimento de uma mulher nos chamou a atenção. Ela revelou que, através desses programas, aprendeu a usar 0 método anticoncepcional conhecido como método do Muco ou Billings. Um método que não é tão simples, mas que, certamente, com uma linguagem clara e simples, pode ser repassado pelo rádio. ${ }^{9}$
Tendo por base o Relatório, em referência, e os dados obtidos nas outras fontes, percebese que, sendo a maioria dos ouvintes do programa A Saúde da Nossa Gente moradora de comunidades rurais, principalmente de povoados dos municípios do estado do Maranhão, é determinante a condição em que essas pessoas viviam, bem como seu estado de carência - falta de rede elétrica, de postos de saúde, de escolas e muitos outros serviços básicos - que apresentam em relação ao conhecimento das temáticas abordadas nos programas exibidos.

Nessa perspectiva, conta Marcelo Amorim que o programa fazia muito sucesso porque "ele adequava a linguagem à comunidade e colocava as pessoas ao vivo", pois "a gente tinha muito cuidado em respeitar o conhecimento popular, porque é a história da pessoa”"10.

0s aspectos citados por Marcelo destacamse nos fragmentos transcritos de um dos programas exibidos, cujo conteúdo foi retirado de um programa gravado, ao vivo, no município de Barreirinhas, local em que foram ouvidos dois depoimentos, cuja temática versa sobre os tabus que existiam naquela região e sobre a alimentação da mulher no seu período pós-parto. 
Chamada: A Rádio Educadora apresenta: 0 Programa Alimentação é Vida, e com vocês a Profa Vera !!!!

(Música: Novilho Mágico-compositor maranhense: Macarrão) ${ }^{11}$

Profa Vera: Ouviremos os depoimentos sobre os tabus que existem com relação à alimentação, os tabus que existem quando a mulher está parida, quando ela está amamentando; e depois vamos ouvir 0 depoimento de um homem, que é 0 Vicente, falando como essa situação está mudando na medida em que ele foi informado.

Primeiro Depoimento

Antonia, da Comunidade de Barra Velha, falando sobre alimentação na época em que a mulher está parida:

Dou exemplo de mim mesmo porque quando a gente levava aquela coisa de dizer que tudo faz mal, então tem aquela coisa de dizer que tudo faz mal, que tal comida faz mal, é remosa, e antigamente eu tinha uma coisa de não comer nada, a coisa podia ta aí, mas eu não podia comer dizendo que era remosa, mas depois que eu comecei a viver uma vida de comunidade, tomando uma experiência daqui outra acolá, hoje eu como tudo; 0 limão inclusive, muita gente dizia se a gente pudesse evitar até de passar debaixo do pé era bom, quanto mais a gente come. Naquela época eu vivia magra porque tinha de emagrecer a falta de comida, mas logo que aquela superstição que a gente tem - aquela superstição que a gente tem mesmo - agora acreditei, viu! Faz mal, é remoso! Agora essa época que me operei de cesariana, e quando estava com 10 dias, tomei um caldo de pato, porque diz que pato é bicho venenoso, é remoso, e eu tomei não senti nada, depois de 15 dias comi mesmo a carne [...] muita gente me perguntou por que eu comi, comi porque a comida não mata ninguém, 0 que mata a gente é a gente com superstição, a gente come é para viver não pra morrer.

\section{Segundo Depoimento}

Vicente, do povoado de Mangas:

É porque a gente lá no meu lugar - lá em Mangas - onde eu resido, o pessoal tinha aquele tabu de não querer aceitar e dizer que fazia mal a gente comer banana, fazer um suco, nera! Uma banana, um maracujá, um mamão, um suco de caju - tudo junto - uma laranja, para a pessoa poder fazer aquela parte de alimentação, principalmente aquelas mulheres que estavam grávidas que não tinha boa alimentação. E quando cheguei na reunião, 0 dia que puxei esse assunto, as mulher tomaram muito contra mim - era uma doidice, ia acabar com o pessoal esse negócio de limão junto com mamão que era uma coisa diferente, laranja, banana, tu é doido! Deus me livre! - E aí comecei fazer uma reunião e levou as experiências e fez, a gente testou e fez, ensinou coma devia se usar e a gente fez elas provarem e agora tá ruim de tirar porque no dia que não tem, às vezes, elas perguntam aonde vai atrás, inté que tem os companheiros que tem uns sítios e tão estourando né! $!^{12}$

Após os depoimentos, a Prof ${ }^{a}$ Vera Salles fez comentários sobre os tabus da alimentação, explicando que a alimentação está relacionada à saúde e ao bom funcionamento do organismo. Abordou também sobre a importância da alimentação no período da gravidez, destacando os tipos de vitaminas e as propriedades inerentes a cada fruta, e ainda ressaltou que a cegueira noturna encontrada naquele município era 
resultante da falta de vitaminas, que são encontradas nas frutas.

Observa-se, nesses relatos, a percepção dos ouvintes entrevistados sobre os conteúdos discutidos nos programas exibidos: questões que envolvem a prática alimentar saudável da mulher no período da gravidez. Esta, por falta de conhecimento sobre 0 assunto, deixa-se levar por crenças em histórias que se arrastam pelo tempo, as quais se refletem nos problemas de saúde enfrentados pelas lactantes daquela comunidade.

Além disso, há de se enfatizar a mudança de atitude que essas pessoas demonstram tanto na compreensão a respeito da importância dos alimentos para a preservação da vida quanto na valorização da convivência e da troca que realizam na "vida em comunidade".

Sob essa perspectiva, é possível pensar em uma Educação Problematizadora que, para Paulo Freire, precisa ser dialógica e mediada por situações de aprendizagem em que o sujeito seja capaz de construir a sua autonomia, considerando que "Já agora ninguém educa ninguém, como tampouco ninguém se educa a si mesmo: os homens se educam em comunhão, mediatizados pelo mundo" (FREIRE, 2009, p. 79).

Nesse sentido, compreender o processo educativo sob a perspectiva dialógica, em que a ação e a reflexão constituem-se elementos essenciais do diálogo, é considerar que existem outras possibilidades de promover a educação, a qual também pode ser para além dos muros da escola, como no caso da Educação não formal, que se reflete aqui em um programa radiofônico, o qual resgata um sentido social de cidadania na medida em que realiza ações que modificam a vida de seus ouvintes interlocutores sociais.

Na construção do diálogo que se estabeleceu entre os ouvintes e os locutores do programa, e em destaque a Prof ${ }^{a}$ Vera Salles, a quem os ouvintes demonstravam muita estima, as cartas funcionavam como instrumento de interação na relação que podemos chamar de ensino/ aprendizagem, uma vez que serviam como suporte para o exercício da escrita de pessoas que não tinham acesso à cultura letrada. Sabe-se que, por força da relação de dominação estabelecida na sociedade de classes, apenas alguns conseguem ter acesso ao direito a conhecer, 0 qual, para Freire (2002), constitui-se um direito fundamental, em que todos e todas tenham a participação do acesso ao universo cultural.

\section{Considerações finais}

Para discussão dos dados e sistematização do texto, utilizamos dez fitas para dialogar com as narrativas das entrevistas, os jornais, manuais e cartas dos ouvintes. Fizemos uso, ainda, de imagens que guardam a memória dos fatos narrados nas fitas, nas cartas e nos depoimentos das pessoas entrevistadas, estratégia que a História Oral propicia ao pesquisador. 
0 programa Alimentação é Vida iniciou a trilogia de programas de divulgação científica idealizados pela Prof ${ }^{a}$ Vera Salles, Alimentação é Vida, A Saúde da Nossa Gente e Vida de Mulher. 0 programa teve a colaboração do cientista biólogo Warwick Estevam Kerr, que, na época, pesquisava plantas alimentícias e medicinais nos povoados do Maranhão, doava sementes para o programa, a fim de que fossem entregues aos ouvintes, que, conforme relatam as cartas, escreviam diariamente solicitando sementes, receitas de alimentação alternativas e remédios caseiros.

A crescente demanda dos ouvintes por informações sobre doenças, saúde, higiene, e alimentação e a parceria que a Prof ${ }^{a}$ Vera Salles firmou com o Unicef, entidade que, na época, incentivava programas de erradicação de doenças relacionadas à pobreza e à falta de infraestrutura na periferia e zona rural do Estado, estimularam a criação do programa A Saúde da Nossa Gente, o qual, mais tarde, incorporou o programa Alimentação é Vida.

0 programa A Saúde da Nossa Gente apresentava em seu conteúdo temas como: plantas alimentícias e medicinais, receitas de alimentação alternativas e remédios caseiros, doenças, dicas de higiene, jornal com notícias sobre saúde e educação, entrevistas com diversos profissionais da área da saúde, educação e representantes do poder público, entre outras discussões voltadas à área da saúde e educação.
Considerando as análises realizadas nos conteúdos e na dinâmica dos dois programas - Alimentação é Vida e A Saúde da Nossa Gente -, pude perceber que, no decurso das décadas de 1980 e 1990, estes delinearam nos espaços da radiofonia maranhense ações de divulgação científica, popularização da ciência ou compreensão pública da ciência, que eram difundidas por meio da utilização de estratégias pedagógicas, as quais independem do espaço da educação ser formal ou não formal.

Como exemplo, vale citar a utilização do instrumento de transposição didática no processo educativo que se estabelecia, pois 0 conteúdo científico produzido pelas academias, apresentado nos programas, era transformado em saber ensinado, considerando o contexto de seus ouvintes.

Quanto aos conteúdos, a abordagem de cada tema obedecia a um planejamento didático, que contemplava não só a informação do tema em questão, mas havia também uma preocupação em se explicar o contexto histórico, as abordagens científicas; as acepções referentes à nomenclatura do termo abordado; os aspectos relacionados ao cotidiano das pessoas a que 0 tema se relacionava, entre outras atividades que foram possíveis de se desenvolver em um espaço não formal de educação, como o rádio-teatro, as entrevistas com especialistas e 0 Jornal da Saúde, apresentado no programa $A$ Saúde $d a$ Nossa Gente. 
Além disso, era expressiva a repetição do tema discutido em diversos programas, em muitos casos, pelas dúvidas apresentadas pelos ouvintes em suas cartas. Havia ainda um artifício de se revisar um tema apresentado por meio do jornalzinho O Bumba e da Cartilha do Agente de Saúde.

As ações dinamizadas nos programas eram mediadas pelo diálogo, o qual se constitui uma atividade pedagógica por excelência. Para Freire (2005), o diálogo produz a conscientização libertadora e transformadora, ou seja, dialógica. Portanto, Freire (2001, p. 15) afirma que a educação está exclusivamente centrada "nos verbos, nos programas, nos discursos".

Nesse sentido, a dialogicidade é compartilhamento da palavra plena de sentido, de vida, de experiência, que se constrói na práxis social, no diálogo sobre atividades criadoras, contextualizadas, em novas leituras e saberes construídos em parceria e, por que não dizer, pretendendo a 'u-topia'.

\section{Referências}

BACHELARD, Gaston. A formação do espírito científico: contribuição para uma psicanálise do conhecimento. Tradução de Estela dos Santos Abreu. Rio de Janeiro: Contraponto, 2007.

BRANDÃ0, Rodrigues Carlos. 0 que é Educação. São Paulo: Brasiliense, 2006.

DESLANDES, S. F. et al. Pesquisa social: teoria, método e criatividade. Petrópolis: Vozes, 1994.
FAYARD, P. La sorpresa de Copérnico: el conocimiento gira alrededor del público. Alambique Didáctica de las Ciencias Experimentales, v.21, p. 9-16, 1999. FEITOSA, Débora Alves. A educação popular enquanto um saber da experiência. In: REUNIÃO ANUAL DA ANPED, 30. Caxambu, 2007. Anais... Caxambu, 2007. FREIRE, P.; NOGUEIRA, A. Que fazer: teoria e prática em educação popular. Petrópolis, 1993.

FREIRE, Paulo. Cartas a Cristina. São Paulo: Paz e Terra, 1994.

Pedagogia da autonomia: saberes necessários à prática educativa. São Paulo: Paz e Terra, 2002.

. Pedagogia do oprimido. Rio de

Janeiro: Paz e Terra, 2009.

GOHN, Maria da Glória. Educação não-formal e cultura política: impactos sobre 0 associativismo do terceiro setor. $2^{\mathrm{a}}$ ed. São Paulo: Cortez, 2001. (Coleção Questões da nossa época; 71).

GONÇALVES, M.F.C. A invenção de uma Rainha de Espada: reatualizações e embaraços na dinâmica política do Maranhão dinástico. São Luís: EDUFMA, 2008.

LEITÃO, P.; ALBAGLI, S. Popularización de la ciencia y la tecnología: una revisión de literatura. In: MARTINEZ, E.; FLOREZ, J. (Comp.). La popularización de la ciencia y la tecnología. México: FCE-Unesco-Red-POP FCE, 1997. p.17-37.

LÉVY-LEBLOND, J. M. Cultura científica: impossível e necessária. In: VOGT, C. (Ed.). Cultura científica: desafios. São Paulo: Edusp/Fapesp, 2006. p. 28-43.

LEWENSTEIN, B. V. Models of public communication of science and technology: version 16 June 2003. Tradução de Francisco Ribeiro Júnior. 2003. Disponível em: < http://communityriskscornell.edu/ BackgroundMaterials/Lewenstein 2003.pdf> . Acesso em: 15 jan. 2009. 
LEWENSTEIN, BV.; BROSSARD, D. Assessing models of public understanding in ELSI outreach materials U.S. Department of Energy, Grant DE-FG02-01ER63173: Final Report. Cornell: Cornell University, 2006.

MARTINEZ, E. La piramide de la popularización de la ciencia y la tecnología. In: MARTINEZ, E.; FLOREZ, J. (Comp.). La popularización de la ciencia y la tecnología. México: FCE-Unesco-Red-POP FCE, 1997. p. 9-16.

MASSARANI, Luisa; MOREIRA, Ildeu Castro. A divulgação científica no Rio de Janeiro: um passeio histórico e o contexto atual. Revista Rio de Janeiro Ciência, Tecnologia e Saúde, Rio de Janeiro, n.11, p. 38-69, 2003.

MEIHY, José Carlos Sebe Bom. Manual de História Oral. $5^{\mathrm{a}}$ ed. São Paulo: Loyola, 2005.

NIETTO, M. El público y las políticas de ciencia y tecnología. Interciencia, v. 27, n. 2, p.80-83, 2002.

PORTELLI, Alessandro. Tentando aprender um pouquinho: algumas reflexões sobre a ética na História Oral. Ética e História Oral. Projeto História, São Paulo, v. 15, p. 13-49, 1997.

SILVA, Acildo Leite da. Memória, tradição oral e a e a afirmação da identidade negra. Movimento - Revista da Faculdade de Educação da Universidade Federal Fluminense, Niterói, $\mathrm{n}^{0}$ 1, maio 2000.

STRECK, Danilo Romeu. A educação popular e a (re)construção do público: há fogo sob as brasas? Revista Brasileira de Educação, v. 11, n ${ }^{0} 32$, p. 272-284, ago 2006.

THOMPSON, Paul. A voz do passado: história oral. Rio de Janeiro: Paz e Terra, 1992.

WYNNE, B. Public Understanding of Science. In: JASSANOF, S.; MARKLE, G.; PETERSEN et al. (Eds.). Handbook of Science and Technology Studies. Tradução de Francisco Ribeiro Júnior. Londres: Sage Publications, 1995. 
The Health of Our Population: the divulgation of science in the fields of non-formal education

\section{Abstract}

This article is the work developed in the research group Scientific Culture and Knowledge Production, Educational Program Graduate Education of the Universidade Federal Maranhão, which focuses its research on science communication, science popularization and public understanding of science, terms used in this work with the same sense, in order to find similarities between the actions of promotion and education. To this, we used oral history as methodology, since in this aspect of qualitative research can explore the relationships between history and memory, which constitutes the essence of this research. The construction of history and memory of the programs is Life Food and Health of Our People, broadcast on Radio Educadoria do Maranhão, in the 1980 and 1990 were made through dialogue with the sources: narratives of persons, tape recordings programs, among others, came under the theory of Freire's Popular Education and non formal education scholars such as Maria da Gloria Ghon allowed us to see that these radio programs consisted non formal important tools of education, because they become dynamic actions which dealt with scientific knowledge as social practice, allowing that the science became part of everyday life in the periphery and the rural community of Maranhão.

\section{Keywords}

Science Communication. Science and technology. Non-Formal Education

\section{La Salud de Nuestro Pueblo:} la communication de la ciencia como una forma de educación no formal

\section{Resumen}

Este artículo es el resultado de un trabajo en el grupo de investigación de la cultura científica y educativa producción de conocimiento del programa pós-graduados en Educación de la Universidade Federal do Maranhão, Brasil, que se centra su investigación en ciencias de la comunicación, la divulgación científica o la comprensión pública de la ciencia, los términos utilizados en este trabajo con el mismo sentido, para buscar similitudes entre las acciones encaminadas a difundir y educar. Para ello, se utilizó la historia oral como una metodología, ya que por este aspecto de la investigación cualitativa para explorar la relación entre la historia y la memoria, lo que constituye la esencia de esta investigación. La construcción de la historia y la memoria de los programas de alimentación es la vida y salud de nuestro pueblo transmitidos por Radio Educadora rural Maranhao, en los años 1980 y 1990 se llevaron a cabo a través del diálogo con las fuentes recogidas: narrativas de las personas, grabaciones en cinta de programas, entre otros, bajo el teórico del eje de la educación popular de Paulo Freire y estudiosos de la educación no formal, como María da Gloria Ghon han permitido ver que estos programas de radio se establecieron importantes herramientas de educación no formal, porque se convierten en acciones dinámicas que tratan con el conocimiento científico como una práctica social, lo que permite por un corto tiempo, la ciencia era parte de la vida cotidiana de las personas en la periferia y en la comunidad rural de Maranhão.

\section{Palabras clave}

Comunicación de la Ciencia. Ciencia y Tecnología. Educación No Formal 


\section{Expediente}

A revista E-Compós é a publicação científica em formato eletrônico da Associação Nacional dos Programas de Pós-Graduação em Comunicação (Compós). Lançada em 2004, tem como principal finalidade difundir a produção acadêmica de pesquisadores da área de Comunicação, inseridos em instituições do Brasil e do exterior.

\section{E-COMPÓS I www.e-compos.org.br I E-ISSN 1808-2599}

Revista da Associação Nacional dos Programas de Pós-Graduação em Comunicação.

Brasília, v.19, n.3, set./dez. 2016.

A identificação das edições, a partir de 2008, passa a ser volume anual com três números.

Indexada por Latindex I www.latindex.unam.mx

\section{CONSELHO EDITORIAL}

Alexandre Farbiarz, Universidade Federal Fluminense, Brasil Alexandre Rocha da Silva, Universidade Federal do Rio Grande do Sul, Brasil Ana Carolina Escosteguy, Pontifícia Universidade Católica do Rio Grande do Sul, Brasil Ana Carolina Rocha Pessôa Temer, Universidade Federal de Goiás, Brasil Ana Regina Barros Rego Leal, Universidade Federal do Piauí, Brasil Andrea França, Pontifícia Universidade Católica do Rio de Janeiro, Brasil André Luiz Martins Lemos, Universidade Federal da Bahia, Brasil Antonio Carlos Hohlfeldt, Pontifícia Universidade Católica do Rio Grande do Sul, Brasil Arthur Ituassu, Pontifícia Universidade Católica do Rio de Janeiro, Brasil Álvaro Larangeira, Universidade Tuiuti do Paraná, Brasil Ângela Freire Prysthon, Universidade Federal de Pernambuco, Brasil César Geraldo Guimarães, Universidade Federal de Minas Gerais, Brasil Cláudio Novaes Pinto Coelho, Faculdade Cásper Líbero, Brasil Daisi Irmgard Vogel, Universidade Federal de Santa Catarina, Brasil Denize Correa Araujo, Universidade Tuiuti do Paraná, Brasil

Eduardo Antonio de Jesus, Pontifícia Universidade Católica de Minas Gerais, Brasil Daniela Zanetti, Universidade Federal do Espirito Santo, Brasil

Eduardo Vicente, Universidade de São Paulo, Brasil

Elizabeth Moraes Gonçalves, Universidade Metodista de São Paulo, Brasil Erick Felinto de Oliveira, Universidade do Estado do Rio de Janeiro, Brasil Francisco Elinaldo Teixeira, Universidade Estadual de Campinas, Brasil Francisco Paulo Jamil Almeida Marques, Universidade Federal do Paraná, Brasil Gabriela Reinaldo, Universidade Federal do Ceará, Brasil

Goiamérico Felício Carneiro Santos, Universidade Federal de Goiás, Brasil Gustavo Daudt Fischer, Universidade do Vale do Rio dos Sinos, Brasil Herom Vargas, Universidade Municipal de São Caetano do Sul, Brasil Itania Maria Mota Gomes, Universidade Federal da Bahia, Brasil Janice Caiafa, Universidade Federal do Rio de Janeiro, Brasil Jiani Adriana Bonin, Universidade do Vale do Rio dos Sinos, Brasil
José Afonso da Silva Junior, Universidade Federal de Pernambuco, Brasil José Luiz Aidar Prado, Pontifícia Universidade Católica de São Paulo, Brasil Juçara Gorski Brittes, Universidade Federal de Ouro Preto, Brasil Kati Caetano, Universidade Tuiuti do Paraná, Brasil Lilian Cristina Monteiro França, Universidade Federal de Sergipe, Brasil Liziane Soares Guazina, Universidade de Brasilia, Brasil Luíza Mônica Assis da Silva, Universidade de Caxias do Sul, Brasil Luciana Miranda Costa, Universidade Federal do Pará, Brasil Malena Segura Contrera, Universidade Paulista, Brasil Monica Martinez, Universidade de Sorocaba, Brasi Maria Ataide Malcher, Universidade Federal do Pará, Brasil Marcia Tondato, Escola Superior de Propaganda e Marketing, Brasil Marcel Vieira Barreto Silva, Universidade Federal da Paraíba, Brasil Maria Clotilde Perez Rodrigues, Universidade de São Paulo, Brasil Maria das Graças Pinto Coelho, Universidade Federal do Rio Grande do Norte, Brasil Mauricio Ribeiro da Silva, Universidade Paulista, Brasil

Mauro de Souza Ventura, Universidade Estadual Paulista, Brasil Márcio Souza Gonçalves, Universidade do Estado do Rio de Janeiro, Brasil Micael Maiolino Herschmann, Universidade Federal do Rio de Janeiro, Brasil Mirna Feitoza Pereira, Universidade Federal do Amazonas, Brasil Nísia Martins Rosario, Universidade Federal do Rio Grande do Sul, Brasil Potiguara Mendes Silveira Jr, Universidade Federal de Juiz de Fora, Brasil Regiane Regina Ribeiro, Universidade Federal do Paraná, Brasil Rogério Ferraraz, Universidade Anhembi Morumbi, Brasil Rose Melo Rocha, Escola Superior de Propaganda e Marketing, Brasil Rozinaldo Antonio Miani, Universidade Estadual de Londrina, Brasil Sérgio Luiz Gadini, Universidade Estadual de Ponta Grossa, Brasil Simone Maria Andrade Pereira de Sá, Universidade Federal Fluminense, Brasil Veneza Mayora Ronsini, Universidade Federal de Santa Maria, Brasil Walmir Albuquerque Barbosa, Universidade Federal do Amazonas, Brasil

\section{CONSELHO CIENTÍFICO}

Cristiane Freitas Guttreind, Pontifícia Universidade Católica do Rio Grande do Sul, Brasil Eduardo Morettin, Universidade de São Paulo, Brasil Felipe Costa Trotta, Universidade Federal Fluminense, Brasil Irene de Araújo Machado, Universidade de São Paulo, Brasil

\section{COMISSÃO EDITORIAL}

Eduardo Antonio de Jesus, Pontifícia Universidade Católica de Minas Gerais, Brasil Osmar Gonçalves dos Reis Filho, Universidade Federal do Ceará, Brasil

\section{CONSULTORES AD HOC}

Geane C. Alzamora, Universidade Federal de Minas Gerais, Brasil Teresinha Cruz Pires, Pontifícia Universidade Católica de Minas Gerais, Brasil

\section{EQUIPE TÉCNICA}

ASSISTENTE EDITORIAL Márcio Zanetti Negrini

REVISÃO DE TEXTOS Press Revisão

EDITORAÇÃO ELETRÔNICA Roka Estúdio

IMAGEM DE CAPA Silas de Paula

\section{COMPÓS I www.compos.org.br}

Associação Nacional dos Programas de Pós-Graduação em Comunicação

Presidente

Edson Fernando Dalmonte

Programa de Pós-Graduação em Comunicação

e Cultura Contemporânea - UFBA

edsondalmonte@uol.com.br

Vice-presidente

Cristiane Freitas Gutfreind

Programa de Pós-Graduação em Comunicação Social - PUC-RS cristianefreitas@pucrs.br

Secretário-Geral

Rogério Ferraraz

Programa de Pós-Graduação em Comunicação

Universidade Anhembi Morumbi

rogerioferraraz@anhembimorumbi.edu.br

CONTATO I revistaecompos@gmail.com 